\title{
Age-related Measurements and Indices of Normal Human Brain Fourth Ventricle: A Computed Tomography Study
}

\author{
Abd El-Wanees A. Al-Awdan, Saadia A. Shalaby, Essam M. Mehlab, Amal M. El Shazly \\ Anatomy Department, Faculty of Medicine, Benha University, Benha City, Egypt \\ Email address: \\ esam-mehlab-100@hotmail.com (E. M. Mehlab)
}

\section{To cite this article:}

Abd El-Wanees A. Al-Awdan, Saadia A. Shalaby, Essam M. Mehlab, Amal M. El Shazly. Age-related Measurements and Indices of Normal Human Brain Fourth Ventricle: A Computed Tomography Study. International Journal of Clinical and Developmental Anatomy.

Vol. 1, No. 2, 2015, pp. 22-31. doi: 10.11648/j.ijcda.20150102.12

\begin{abstract}
Objectives: To detect average dimensions and indices of normal brain cerebral hemispheres and fourth ventricles in relation to age and gender. Subjects \& Methods: 135 subjects; 70 males (M) and 65 females (F) were categorized into 4 age groups (G): GM1 \& GF1 included subjects $<20$ years old, GM2 \& GF2 included subjects aged 20-40 years, GM3 \& GF3 included subjects aged 40-60 years and GM4 \& GF4 included subjects $>60$ years old. CT imaging was conducted according to Agapejev; using high resolution scanner for measuring the fourth ventricle; the fourth ventricular anteroposterior diameter (AP), laterolateral diameter and fourth ventricular indices. Results: As regard the measured parameter of the fourth ventricle, the anteroposterior diameter (AP) and the laterolateral diameter (LL) showed a significant increase after the age of forty in both sexes. The indices of the fourth ventricle (AP/CR) and (AP/ff) showed no significant changes with age and sex but these indices had some degree of changes during human life time. On the other hand the only index that does not suffer influence of age and sex at all, it was (AP/LL) index. Considering the sex difference in ventricular dilatation in the present work, AP/LL was the only parameters which showed no difference between males and females so considered as (sentinel index of the fourth ventricle). Conclusion: The dimensions of the normal brain ventricles increased gradually and steadily between the age of one and fifty years, however they increased markedly and significantly thereafter in both sexes. This may be due to a physiological brain atrophy that may be encountered in most elderly individuals. Ventricular system was larger in males than that of females of all age groups.
\end{abstract}

Keywords: Human Brain, Fourth Ventricle, CT Study

\section{Introduction}

Age-related changes in brain structure result from a complex interplay among various neurobiological processes, which may contribute to more complex trajectories than what can be described by simple linear or quadratic models. Most brain structures do not follow a simple path throughout adult life. Cerebral atrophy has long been recognized as a prominent feature of normal aging process. However, accelerated decline in high age is not the norm of healthy brain aging and sever atrophy occurred only in demented elderly individuals and not in normal aged ${ }^{(1,2)}$.

Neuroimaging studies have identified several forms of age-related change in brain structure that are relevant as potential mediators of age-related changes in cognitive performance. Prominent among these is age-related decline in the volume of cerebral gray matter, particularly in prefrontal regions. Age-related decline is also evident in cerebral white matter volume, although with a different trajectory. Whereas the age-related decline in gray matter volume is relatively linear from younger adulthood, the corresponding decline in white matter tends to be nonlinear, with a plateau in middle-age and additional decline, beyond that of gray matter, in later adulthood ${ }^{(3,4)}$.

On contrary to these data, recently, Ziegler et al. ${ }^{(5)}$ and Taki et al. (6) found a significant positive correlation between the annual rate of gray matter volume change and age indicating that gray matter volume shows not linear but accelerated loss with age and so documented evaluating the annual rate of the gray matter volume change with age in healthy subjects to understand how gray matter volume changes with aging in each brain region and to anticipate what cognitive functions are likely to show accelerated decline with aging.

The cerebral ventricles are a series of interconnected, fluid-filled spaces that lie in the core of the forebrain and 
brainstem. The presence of ventricular spaces in the various subdivisions of the brain reflects the fact that the ventricles are the adult derivatives of the open space or lumen of the embryonic neural tube. The largest of cerebral ventricles are the lateral ventricles which are located in the center of the brain one within each of the cerebral hemispheres. In frontal sections, ventral surface of lateral ventricles is usually defined by the basal ganglia, the dorsal surface by the corpus callosum, and the medial surface by the septum pellucidum $^{(7,8,9)}$.

The current prospective comparative study aimed to detect the average dimensions and indices of the normal brain cerebral hemispheres and fourth ventricles in relation to age and gender as a trial to provide standard schedules of the normal brain parameters.

\section{Subjects \& Methods}

The current study was designed as a comparative study of CT brain scanning findings of normal subjects. Inclusion criteria included healthy subjects free from any clinical manifestations indicating brain pathology as judged by clinical examination conducted at Department of Neurology, Benha University Hospital. All CT imaging were conducted and analyzed at Diagnostic Radiology Department, Benha University Hospital. Analysis of CT images and determination of points of interest were determined by the authors and then measurements were analyzed and compared at Anatomy Department.

Exclusion criteria included history of previous brain trauma, cerebro-vascular accidents, seizures, intellectual deterioration, alcoholism and dementia. CT scans showing asymmetrical head position and presence of any detectable lesion even if all the other CT of the same patient has been normal were also excluded from this study.

The study included 135 subjects fulfilled the inclusion criteria; 70 males and 65 females. Subjects were categorized into 4 age groups $(\mathrm{G})$ : $\mathrm{G} 1$ included subjects younger than 20 years of both sexes (GM1 \& GF1), G2 included subjects aged 20 to 40 years of both sexes (GM2 \& GF2), G3 included subjects aged 40 to 60 years of both sexes (GM3 \& GF3) and G4 included subjects older than 60 years of both sexes (GM4 \& GF4).

CT imaging was conducted without sedation, anesthesia or intravenous contrast administration. The procedure was performed according to Agapejev ${ }^{(10)}$; using high resolution scanner with the scanning at an average tilt of $20^{\circ}$ from the cantho-meatal line that extends from the lateral epicanthus of the eye to the external acoustic meatus. Individuals were put in a supine position, centralized, fixed and their heads were placed in the gantry of the apparatus in a slightly hyper-extended position. About 15 serial cross sections (cuts) of the brain for every case were taken in a display field of the axial plan. The thickness of each examined contagious tissue section was $5-10 \mathrm{~mm}$ between each cut and the next one. The chosen parameters were measured at low levels of the CT scan cuts ${ }^{(11)}$.

\subsection{Studied Parameters}

Dimensions and indices of the fourth ventricle (Agapejev, 2002) (figure 1):

\subsubsection{The Largest Anteroposterior Width (AP)}

- It is the maximal anteroposterior width of the fourth ventricle. It is represented by a longitudinal line between the widest two points of the fourth ventricle.

\subsubsection{The Laterolateral Width in the Same Slice (LL)}

- It is the maximal width of the fourth ventricle; it is represented by a transverse line between the widest two points of the fourth ventricle.

\subsubsection{Fourth Ventricular Indices (AP/CR), (AP/LL) and $(\boldsymbol{A P} / \boldsymbol{f f})$}

(AP/CR): The ratio between the maximal anteroposterior diameter of the fourth ventricle and the maximum intercranial diameter. CR (It is represented by a transverse line connecting the widest distance between the inner skull tables in the same slice of).

- (AP/LL): The ratio between the maximal anteroposterior diameter of the fourth ventricle and the maximal width of the fourth ventricle at the same slice.

(AP/ff): The ratio between the maximal anteroposterior diameter of the fourth ventricle and the bifrontal distance of the anterior horn, of the lateral ventricles. ff (it is represented by a transverse line connecting the inner skull tables at the same level of the bifrontal distance).

\subsection{Statistical Analysis}

Obtained data were presented as mean \pm SD. Results were analyzed using Wilcoxon; ranked test for unrelated data (Ztest). Statistical analysis was conducted using the SPSS (Version 15, 2006) for Windows statistical package. P value $<0.05$ was considered statistically significant. 


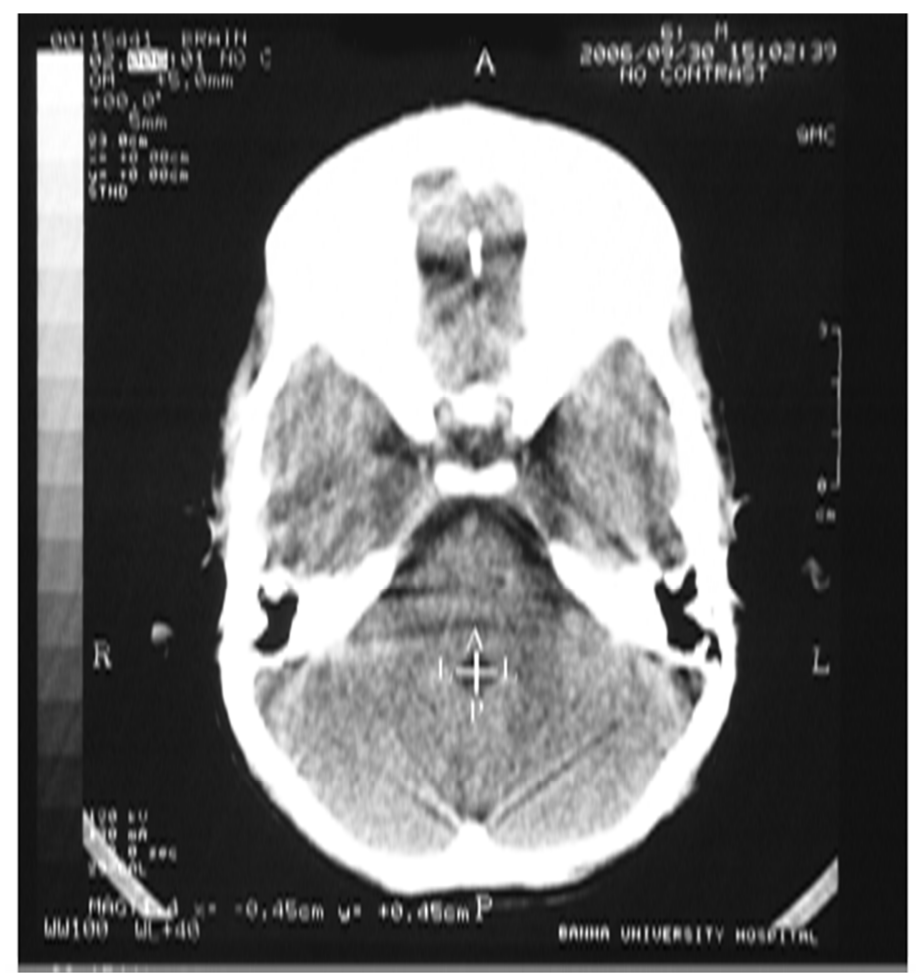

Figure (1). An axial CT image showing the fourth ventricle.

(AP): Anteroposterior diameter of the fourth ventricle.

(LL): Latrolateral diameter of fourth ventricle.

\section{Results}

CT was carried out on the brain of 135 normal healthy individuals including 65 females (F) and 70 males (M), with an age ranged from three months to eighty four years old. The cases were divided into four main age groups:

Group $_{1}\left(G_{1}\right)=$ younger than 20 years old.

Group $2(\mathrm{G} 2)=$ from 20 to 39 years old.

Group $3(\mathrm{G} 3)=$ from 40 to 59 years old

Group $4(\mathrm{G} 4)>60$ years old.

These individuals were gathered in (sex/age) subgroups as shown in table (1). The results were obtained from CT films and the variables were recorded from each group and analyzed statistically.

\subsection{The Recorded Parameters in Male Groups}

Fourth ventricle:

\subsubsection{The Maximum Anteroposterior Diameter of the Fourth Ventricle (AP)}

In $\left(\mathrm{MG}_{1}\right)\left(\mathrm{MG}_{2}\right),\left(\mathrm{MG}_{3}\right)$ and $\left(\mathrm{MG}_{4}\right)$ groups, the mean values of the $4^{\text {th }}$ ventricle were $9.24 \pm 3.08 \mathrm{~mm}, 10.3 \pm 2.73$ $\mathrm{mm}, 13.9 \pm 1.56 \mathrm{~mm}$ and $16.3 \pm 0.91 \mathrm{~mm}$ respectively. These data showed no statistical significant difference between $\left(\mathrm{MG}_{1}\right)$ and $\left(\mathrm{MG}_{2}\right)$. However in $\left(\mathrm{MG}_{2}\right),\left(\mathrm{MG}_{3}\right)$ and $\left(\mathrm{MG}_{4}\right)$ there were a highly statistical significant increase in the mean value obtained from these parameters in the three conscutive age groups (tables 2\&3) and (Figures 2- 5).

\subsubsection{The Laterolateral Diameter of the Fourth Ventricle (LL)}

In $\left(\mathrm{MG}_{1}\right)\left(\mathrm{MG}_{2}\right),\left(\mathrm{MG}_{3}\right)$ and $\left(\mathrm{MG}_{4}\right)$ groups, The mean values of the $4^{\text {th }}$ ventricle were $9.24 \pm 3.08 \mathrm{~mm}, 10.3 \pm 2.73$ $\mathrm{mm}, 13.9 \pm 1.56 \mathrm{~mm}$ and $16.3 \pm 0.91 \mathrm{~mm}$ respectively. These data showed no statistical significant difference between $\left(\mathrm{MG}_{1}\right)$ and $\left(\mathrm{MG}_{2}\right)$. However in $\left(\mathrm{MG}_{2}\right),\left(\mathrm{MG}_{3}\right)$ and $\left(\mathrm{MG}_{4}\right)$ there were a highly statistical significant increase in the mean value obtained from these parameters in the three conscutive age groups (tables 2\&3) and (Figures 2- 5).

\subsubsection{The Maximum Intercranial Diameter (CR)}

In $\left(\mathrm{MG}_{1}\right)\left(\mathrm{MG}_{2}\right),\left(\mathrm{MG}_{3}\right)$ and $\left(\mathrm{MG}_{4}\right)$ groups, The mean values of these parameter were $118.4 \pm 6.34 \mathrm{~mm}, 120 \pm$ $5.22 \mathrm{~mm}, 121 \pm 6.03 \mathrm{~mm}$ and $119 \pm 4.68 \mathrm{~mm}$ respectively. These data showed no significant statistical change in this parameter among the all four tested age groups in males (tables 2\&3) and (Figures 2- 5).

\subsubsection{Fourth Ventricular Indices (AP/CR), (AP/LL) and $(A P / f f)$}

- In $\left(\mathrm{MG}_{1}\right)\left(\mathrm{MG}_{2}\right),\left(\mathrm{MG}_{3}\right)$ and $\left(\mathrm{MG}_{4}\right)$ groups. The mean values of $(\mathrm{AP} / \mathrm{CR})$ were $0.08 \pm 0.03 \mathrm{~mm}, 0.09 \pm$ $0.02 \mathrm{~mm}, 0.7 \pm 2.4$ and $0.14 \pm 0.01 \mathrm{~mm}$ respectively. These obtained results showed no statistical significant changes between the all four tested groups.

While the mean values of $(\mathrm{AP} / \mathrm{LL})$ were $1 \pm 0$ in the all four groups with no statistical change with age at all. And the mean values of $\mathrm{AP} / \mathrm{ff}$ were $0.32 \pm 0.13,0.33 \pm 0.1,0.41$ 
\pm 0.06 and $0.41 \pm 0.03$ respectively. These obtained result showed a statistical significant increase only between $\left(\mathrm{MG}_{2}\right)$ and $\left(\mathrm{MG}_{3}\right)$ and there is no statistical significant changes in these index between the other male groups (tables $2 \& 3$ ) and (Figures 2- 5).

Table (1). Showing the mean and standard deviation of age / years in the used age groups in both sexes.

\begin{tabular}{lllll}
\hline \multirow{2}{*}{$\begin{array}{l}\text { Age group } \\
\text { / yrs }\end{array}$} & Sex & \multicolumn{2}{l}{ Males $(\mathbf{M})$} & \multicolumn{3}{l}{ Females $(\mathbf{F})$} \\
\cline { 2 - 5 } & $\mathbf{N}$ & Mean \pm SD & N & Mean \pm SD \\
\hline G1 $(0-19$ yrs $)$ & 21 case & $9.79 \pm 5.64$ & 18 case & $10.1 \pm 7.23$ \\
G2 $(20-39$ yrs $)$ & 22 case & $28.3 \pm 5.58$ & 26 case & $30.17 \pm 4.82$ \\
G3 $(40-59$ yrs $)$ & 17 case & $50.4 \pm 5.33$ & 11 case & $49.8 \pm 4.96$ \\
G4 $>60$ yrs & 10 case & $69+8.63$ & 10 case & $66.6 \pm 4.35$ \\
\hline
\end{tabular}

$\mathrm{N}=$ Number of cases in each age/sex group.

$\mathrm{SD}=$ Standard deviation

$\mathrm{G}=$ Group $\mathrm{M}=$ Male $\mathrm{F}=$ Female

Table (2). The measured parameters (in $\mathrm{mm}$ ) of the fourth ventricle in different male groups.

\begin{tabular}{|c|c|c|c|c|c|c|}
\hline & AP & $\mathbf{L L}$ & CR & $\mathbf{A P} / \mathbf{C R}$ & AP/LL & $\mathbf{A P} \backslash \mathbf{f f}$ \\
\hline MG1 & $\begin{array}{l}9.24 \pm \\
3.08\end{array}$ & $\begin{array}{l}9.24 \pm \\
3.08\end{array}$ & $\begin{array}{l}118.4 \pm \\
6.34\end{array}$ & $\begin{array}{l}0.08 \pm \\
0.03\end{array}$ & $1 \pm 0$ & $0.318 \pm 0.13$ \\
\hline MG2 & $\begin{array}{l}10.3 \pm \\
2.73\end{array}$ & $\begin{array}{l}10.3 \pm \\
2.73\end{array}$ & $\begin{array}{l}120 \pm \\
5.22\end{array}$ & $\begin{array}{l}0.09 \pm \\
0.02\end{array}$ & $1 \pm 0$ & $0.33 \pm 0.1$ \\
\hline MG3 & $\begin{array}{l}13.9 \pm \\
1.56\end{array}$ & $\begin{array}{l}13.9 \pm \\
1.56\end{array}$ & $\begin{array}{l}121 \pm \\
6.03\end{array}$ & $0.7 \pm 2.4$ & $1 \pm 0$ & $0.41 \pm 0.06$ \\
\hline MG4 & $\begin{array}{l}16.3 \pm \\
0.91\end{array}$ & $\begin{array}{l}16.3 \pm \\
0.91\end{array}$ & $\begin{array}{l}119 \pm \\
4.68\end{array}$ & $\begin{array}{l}0.14 \pm \\
0.01\end{array}$ & $1 \pm 0$ & $0.41 \pm 0.03$ \\
\hline
\end{tabular}

Table (3). Comparison between data/mm of the fourth ventricle in successing male age group.

\begin{tabular}{lllll}
\hline & MG1 & MG2 & t & P \\
\hline $\mathrm{AP}$ & $9.24 \pm 3.08$ & $10.3 \pm 2.73$ & 1.19 & $>0.05$ \\
$\mathrm{LL}$ & $9.24 \pm 3.08$ & $10.3 \pm 2.73$ & 1.19 & $>0.05$ \\
$\mathrm{CR}$ & $118.4 \pm 6.34$ & $120 \pm 5.22$ & 0.9 & $>0.05$ \\
$\mathrm{AP} / \mathrm{CR}$ & $0.08 \pm 0.03$ & $0.09 \pm 0.02$ & 1.28 & $>0.05$ \\
$\mathrm{AP} / \mathrm{CL}$ & $1 \pm 0$ & $1 \pm 0$ & - & - \\
$\mathrm{AP} \backslash \mathrm{ff}$ & $0.32 \pm 0.13$ & $0.33 \pm 0.1$ & 0.28 & $>0.05$ \\
& $\mathrm{MG} 2$ & $\mathrm{MG} 3$ & $\mathrm{t}$ & $\mathrm{P}$ \\
$\mathrm{AP}$ & $10.3 \pm 2.73$ & $13.9 \pm 1.56$ & 5.19 & $<0.001$ \\
$\mathrm{LL}$ & $10.3 \pm 2.73$ & $13.9 \pm 1.56$ & 5.19 & $<0.001$ \\
$\mathrm{CR}$ & $120 \pm 5.22$ & $121 \pm 6.03$ & 0.54 & $>0.05$ \\
$\mathrm{AP} / \mathrm{CR}$ & $0.09 \pm 0.02$ & $0.7 \pm 2.4$ & 1.05 & $>0.05$ \\
$\mathrm{AP} / \mathrm{LL}$ & $1 \pm 0$ & $1 \pm 0$ & - & - \\
$\mathrm{AP} \backslash \mathrm{ff}$ & $0.33 \pm 0.1$ & $0.41 \pm 0.06$ & 3.1 & $<0.01$ \\
& $\mathrm{MG} 3$ & $\mathrm{MG} 4$ & $\mathrm{t}$ & $\mathrm{P}$ \\
$\mathrm{AP}$ & $13.9 \pm 1.56$ & $16.3 \pm 0.91$ & 5.05 & $<0.001$ \\
$\mathrm{LL}$ & $13.9 \pm 1.56$ & $16.3 \pm 0.91$ & 5.05 & $<0.001$ \\
$\mathrm{CR}$ & $121 \pm 6.03$ & $119 \pm 4.68$ & 0.96 & $>0.05$ \\
$\mathrm{AP} / \mathrm{CR}$ & $0.7 \pm 2.4$ & $0.14 \pm 0.01$ & 0.96 & $>0.05$ \\
$\mathrm{AP} / \mathrm{LL}$ & $1 \pm 0$ & $1 \pm 0$ & - & - \\
$\mathrm{AP} \backslash \mathrm{ff}$ & $0.41 \pm 0.06$ & $0.41 \pm 0.03$ & - & - \\
\hline
\end{tabular}

- $\mathrm{P}>0.05=$ Insignificant.

- $\mathrm{P}<0.05=$ Significant.

- $\mathrm{P}<0.01=$ highly significant.

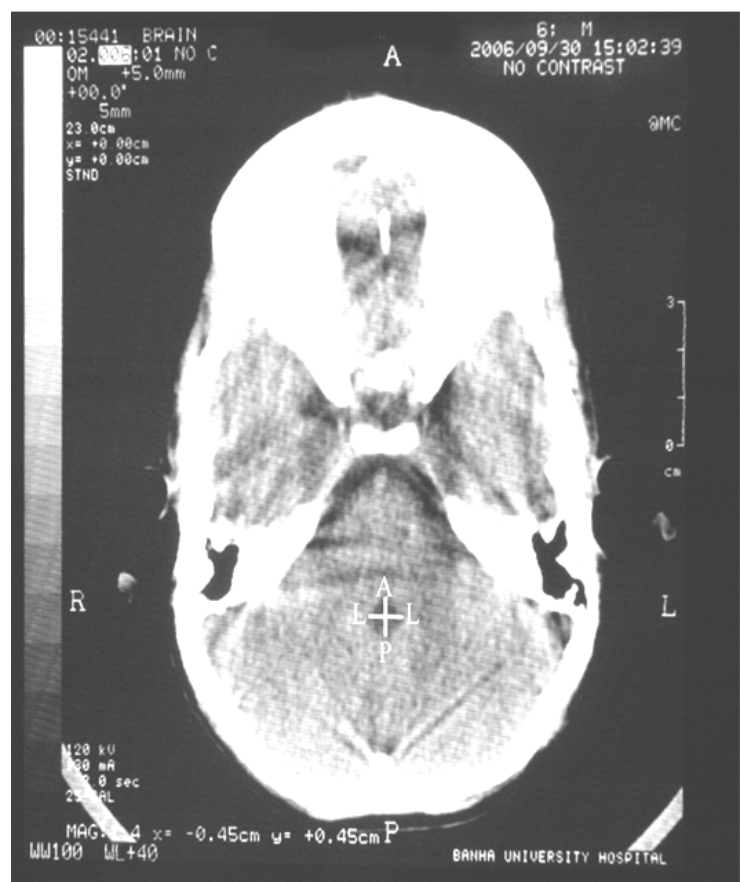

Figure (2). Axial CT image of fourth ventricular maximum width of 6 years old male showing.

- The anteroposterior diameter of the fourth ventricle $(\mathrm{AP})=9.23 \mathrm{~mm}$.

- The laterolateral diameter of the fourth ventricle (LL) $=$ $9.23 \mathrm{~mm}$

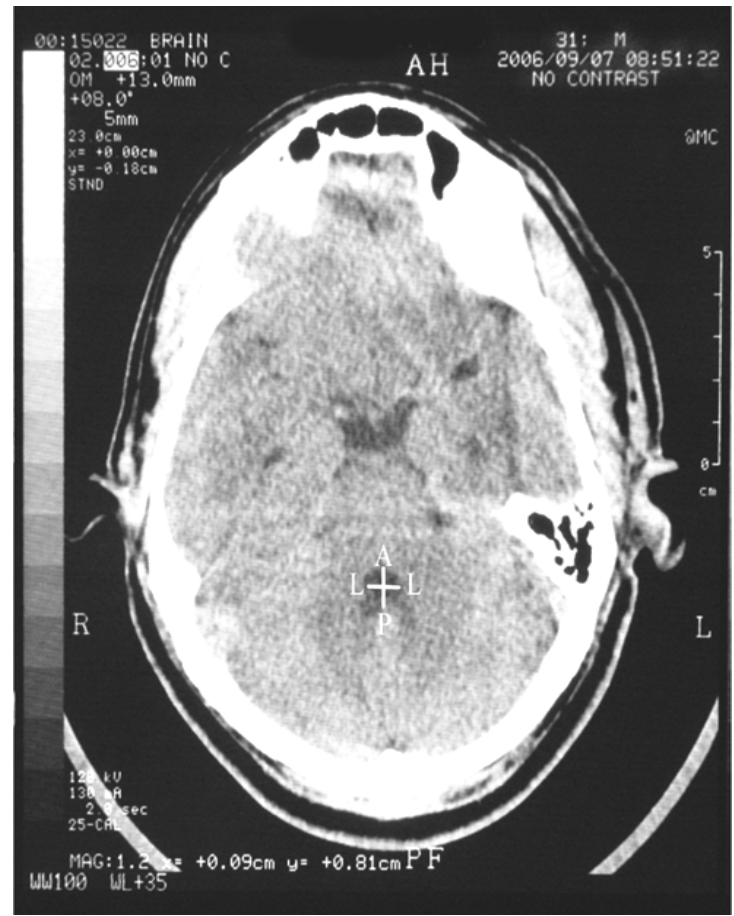

Figure (3). Axial CT image of fourth ventricular maximum width of a male aged 31 years old showing.

- The anteroposterior diameter of the fourth ventricle (AP) $=7.32 \mathrm{~mm}$.

- The laterolateral diameter of the fourth ventricle $(\mathrm{LL})=$ $7.32 \mathrm{~mm}$ 


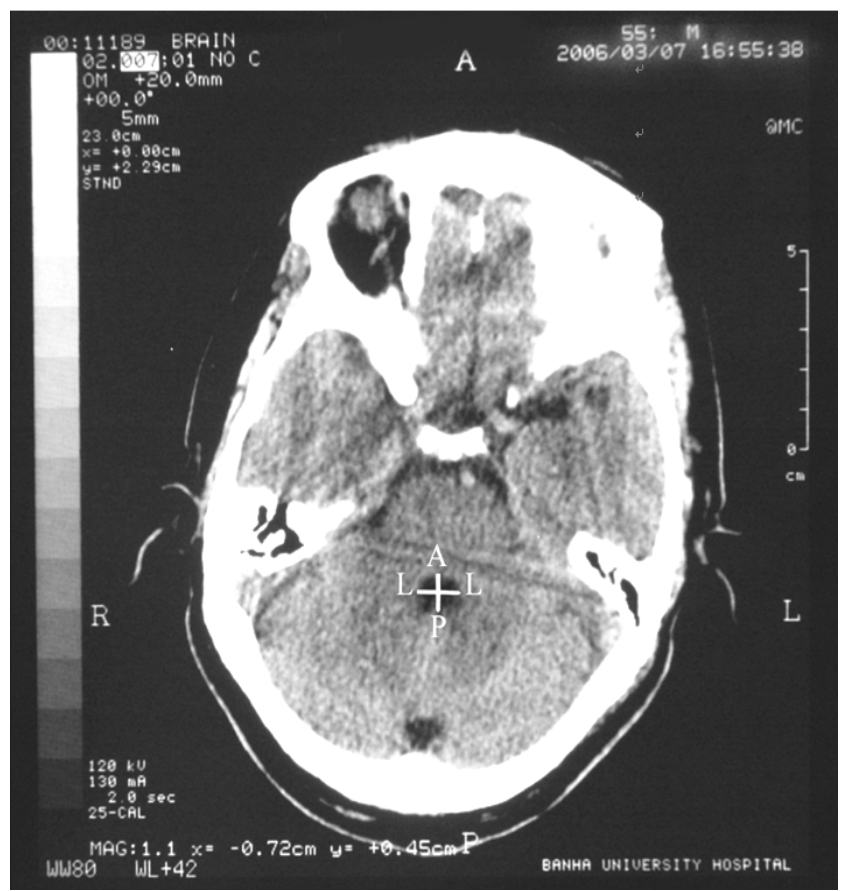

Figure (4). Axial CT image of fourth ventricular maximum width of a male aged 55 years old showing.

- The anteroposterior diameter of the fourth ventricle (AP) $=12.87 \mathrm{~mm}$.

- The laterolateral diameter of the fourth ventricle $(\mathrm{LL})=$ $12.87 \mathrm{~mm}$.

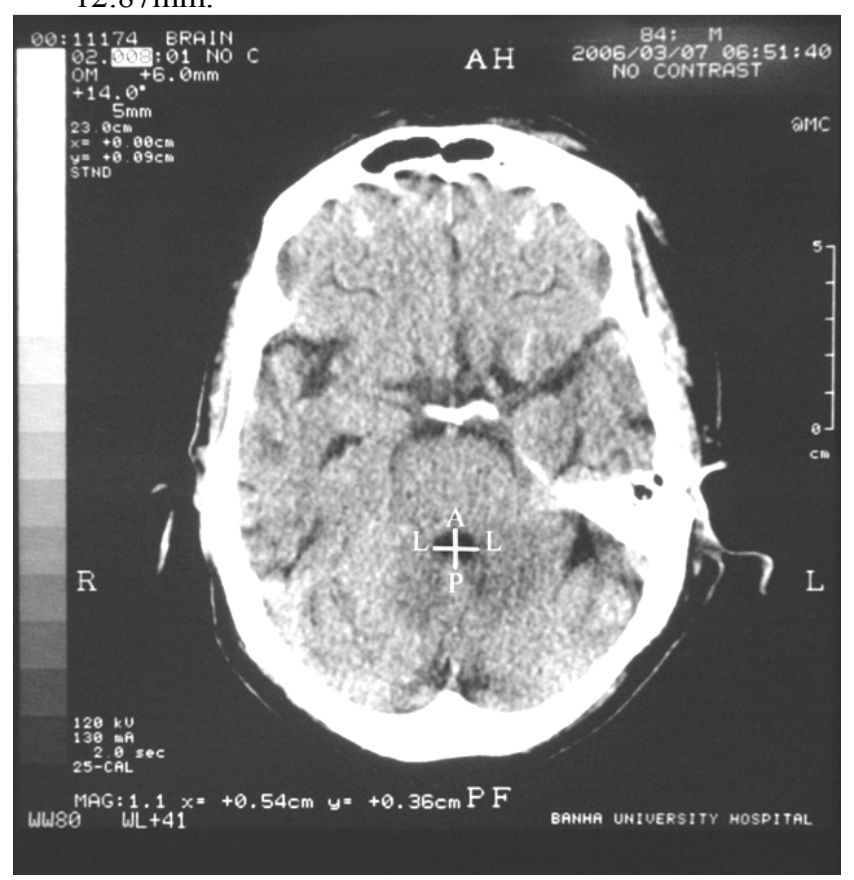

Figure (5). Axial CT image of fourth ventricular maximum width of a male aged 84 years old showing.

- The anteroposterior diameter of the fourth ventricle $(\mathrm{AP})=15 \mathrm{~mm}$.

- The laterolateral diameter of the fourth ventricle $(\mathrm{LL})=$ $15 \mathrm{~mm}$.

\subsection{The recorded Parameter in Female Groups}

* Fourth ventricle:

\subsubsection{The Maximal Anteroposterior Diameter of the Fourth Ventricle (AP)}

In $\left(\mathrm{FG}_{1}\right),\left(\mathrm{FG}_{2}\right),\left(\mathrm{FG}_{3}\right)$ and $\left(\mathrm{FG}_{4}\right)$ groups. The mean values of the (AP) were $9.88 \pm 2.52 \mathrm{~mm}, 9.99 \pm 1.28 \mathrm{~mm}, 12.1 \pm$ $0.92 \mathrm{~mm}$ and $14.2 \pm 1.32 \mathrm{~mm}$ respectively. These data showed no statistical insignificant increase difference between $\left(\mathrm{MG}_{1}\right)$ and $\left(\mathrm{MG}_{2}\right)$. However there are a highly statistical significant increase in this parameter in the next three conscutive age groups in females, (Tables 4-5) and (figures 6-9).

\subsubsection{The Laterolateral Diameter of the Fourth Ventricle (LL)}

In $\left(\mathrm{FG}_{1}\right),\left(\mathrm{FG}_{2}\right),\left(\mathrm{FG}_{3}\right)$ and $\left(\mathrm{FG}_{4}\right)$ groups. The mean values of the (AP) were $9.88 \pm 2.52 \mathrm{~mm}, 9.99 \pm 1.28 \mathrm{~mm}, 12.1 \pm$ $0.92 \mathrm{~mm}$ and $14.2 \pm 1.32 \mathrm{~mm}$ respectively. These data showed no statistical insignificant increase difference between $\left(\mathrm{MG}_{1}\right)$ and $\left(\mathrm{MG}_{2}\right)$. However there are a highly statistical significant increase in this parameter in the next three conscutive age groups in females, (Tables 4-5) and (figures 6-9).

\subsubsection{The Maximal Intercranial Diameter (CR)}

In $\left(\mathrm{FG}_{1}\right),\left(\mathrm{FG}_{2}\right),\left(\mathrm{FG}_{3}\right)$ and $\left(\mathrm{FG}_{4}\right)$ groups. The mean values of the these parameter were $112 \pm 15.6 \mathrm{~mm}, 119 \pm 4.29 \mathrm{~mm}$, $116 \pm 3.91 \mathrm{~mm}$ and $116 \pm 2.57 \mathrm{~mm}$ respectively. These data showed no significant statistical change in this parameter among the All four tested age groups in females, (Tables 4-5) and (figures 6-9).

\subsubsection{The Fourth Ventricular Indices $(A P / C R),(A P / L L)$ and $(A P / f f)$}

- In (FG1), (FG2), (FG3) and (FG4) groups. The mean values of $(\mathrm{AP} / \mathrm{CR})$ were $0.09 \pm 0.02 \mathrm{~mm}, 0.13 \pm 0.19$ $\mathrm{mm}, 0.1 \pm 0.01 \mathrm{~mm}$ and $0.12 \pm 0.01 \mathrm{~mm}$ respectively. These obtained results showed no statistical significant change in these parameters between the first three consecutive age groups however there was a statistical significant difference between (FG3 and FG4) groups regarding this index.

- The values of (AP/LL) were $1+0$ in the all four groups with no statistical change with age at all. And the values of $(\mathrm{AP} / \mathrm{ff})$ were $0.35+0.1,0.34+0.06,0.37+0.04$ and $0.4+0.04$ respectively. These obtained results showed no statistical significant change with age in the Allfemale groups, (Tables 4-5) and (figures 6-9).

Table (4). The measured parameters (in $\mathrm{mm}$ ) of the fourth ventricle in different female groups.

\begin{tabular}{lllllll}
\hline & AP & LL & CR & AP/CR & AP/LL & AP\ff \\
\hline \multirow{2}{*}{ FG1 } & \multirow{2}{*}{$9.88 \pm 2.52$} & $9.88 \pm$ & $112 \pm$ & $0.09 \pm$ & $1 \pm 0$ & $0.35 \pm$ \\
& & 2.52 & 15.6 & 0.02 & & 0.1 \\
FG2 & \multirow{2}{*}{$5.99 \pm 1.28$} & $9.99 \pm 1.2$ & $119 \pm$ & $0.13 \pm$ & $1 \pm 0$ & $0.34 \pm$ \\
& & 8 & 4.29 & 0.19 & & 0.06 \\
FG3 & \multirow{2}{*}{$12.1 \pm 0.92$} & $12.1 \pm 0.9$ & $116 \pm$ & $0.1 \pm$ & $1 \pm 0$ & $0.37 \pm$ \\
& & 2 & 4.93 & 0.01 & & 0.04 \\
FG4 & \multirow{2}{*}{$14.2 \pm 1.32$} & $14.2 \pm 1.3$ & $116 \pm$ & $0.12 \pm$ & $1 \pm 0$ & $0.4 \pm 0.04$ \\
& & 2 & 25.7 & 0.01 & & \\
\hline
\end{tabular}


Table (5). Comparison between data/mm of the fourth ventricle in the successing female age groups.

\begin{tabular}{lllll}
\hline & FG1 & FG2 & t & P \\
\hline $\mathrm{AP}$ & $9.88 \pm 2.52$ & $9.99 \pm 1.28$ & 0.17 & $>0.05$ \\
$\mathrm{LL}$ & $9.88 \pm 2.52$ & $9.99 \pm 1.28$ & 0.17 & $>0.05$ \\
$\mathrm{CR}$ & $112 \pm 15.6$ & $119 \pm 4.29$ & 1.86 & $>0.05$ \\
$\mathrm{AP} / \mathrm{CR}$ & $0.09 \pm 0.02$ & $0.13 \pm 0.19$ & 1.07 & $>0.05$ \\
$\mathrm{AP} / \mathrm{LL}$ & $1 \pm 0$ & $1 \pm 0$ & 1.27 & $>0.05$ \\
$\mathrm{AP} \backslash \mathrm{ff}$ & $0.35 \pm 0.1$ & $0.34 \pm 001$ & 0.38 & $>0.05$ \\
& $\mathrm{FG} 2$ & $\mathrm{FG} 3$ & $\mathrm{t}$ & $\mathrm{P}$ \\
$\mathrm{AP}$ & $9.99 \pm 1.28$ & $12.1 \pm 0.92$ & 5.64 & $<0.001$ \\
$\mathrm{LL}$ & $9.99 \pm 1.28$ & $12.1 \pm 0.92$ & 5.64 & $<0.001$ \\
$\mathrm{CR}$ & $119 \pm 4.29$ & $116 \pm 4.93$ & 1.95 & $>0.05$ \\
$\mathrm{AP} / \mathrm{CR}$ & $0.13 \pm 0.19$ & $0.1 \pm 0.01$ & 0.8 & $>0.05$ \\
$\mathrm{AP} / \mathrm{LL}$ & $1 \pm 0$ & $1 \pm 0$ & 1.27 & $>0.05$ \\
$\mathrm{AP} \backslash \mathrm{ff}$ & $0.34 \pm 001$ & $0.37 \pm 0.04$ & 1.78 & $>0.05$ \\
& $\mathrm{FG} 3$ & $\mathrm{FG} 4$ & $\mathrm{t}$ & $\mathrm{P}$ \\
$\mathrm{AP}$ & $12.1 \pm 0.92$ & $14.2 \pm 1.32$ & 4.19 & $<0.001$ \\
$\mathrm{LL}$ & $12.1 \pm 0.92$ & $14.2 \pm 1.32$ & 4.19 & $<0.001$ \\
$\mathrm{CR}$ & $116 \pm 3.91$ & $116 \pm 2.57$ & 0 & - \\
$\mathrm{AP} / \mathrm{CR}$ & $0.1 \pm 0.01$ & $0.12 \pm 0.01$ & 4.58 & $<0.001$ \\
$\mathrm{AP} / \mathrm{LL}$ & $1 \pm 0$ & $1 \pm 0$ & - & - \\
$\mathrm{AP} \backslash \mathrm{ff}$ & $0.37 \pm 0.04$ & $0.4 \pm 0.04$ & 1.72 & $>0.05$ \\
\hline
\end{tabular}

- $\quad \mathrm{P}>0.05=$ Insignificant.

- $\mathrm{P}<0.05=$ Significant

- $\mathrm{P}<0.01=$ highly significant

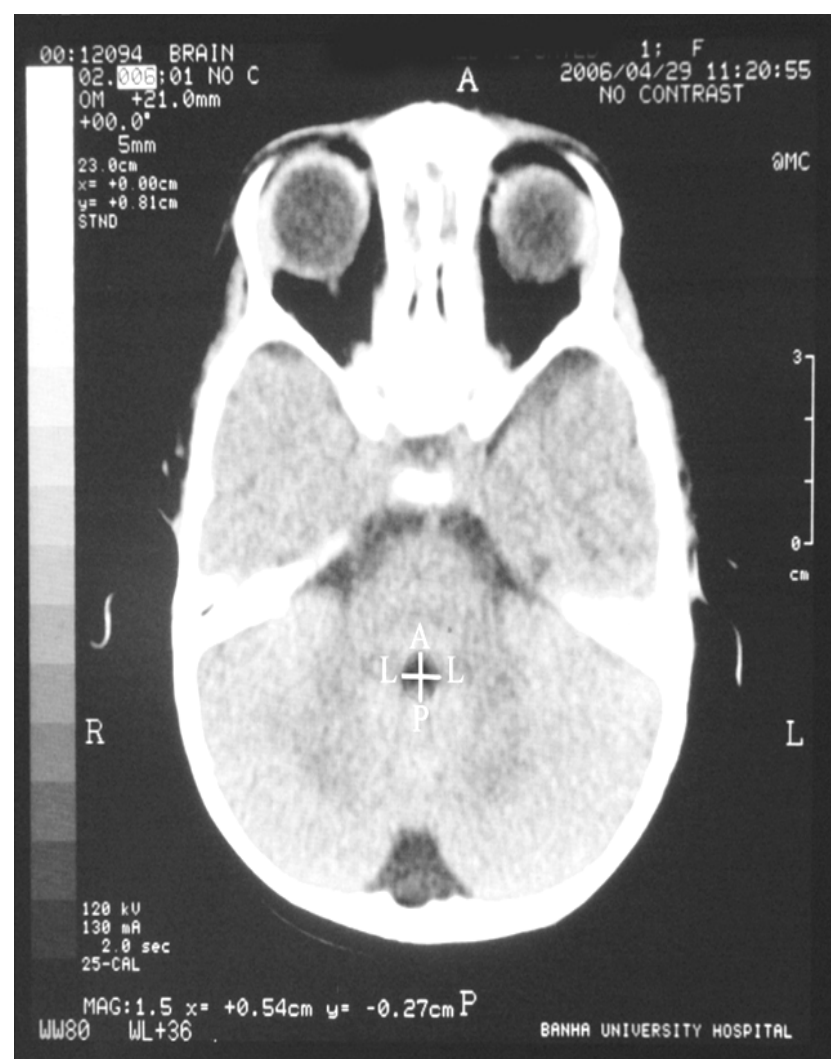

Figure (6). Axial CT image of fourth ventricular maximum width of a female 1 year old showing.

- The anteroposterior diameter of the fourth ventricle (AP) $=10 \mathrm{~mm}$.

- The laterolateral diameter of the fourth ventricle $(\mathrm{LL})=$ $10 \mathrm{~mm}$.

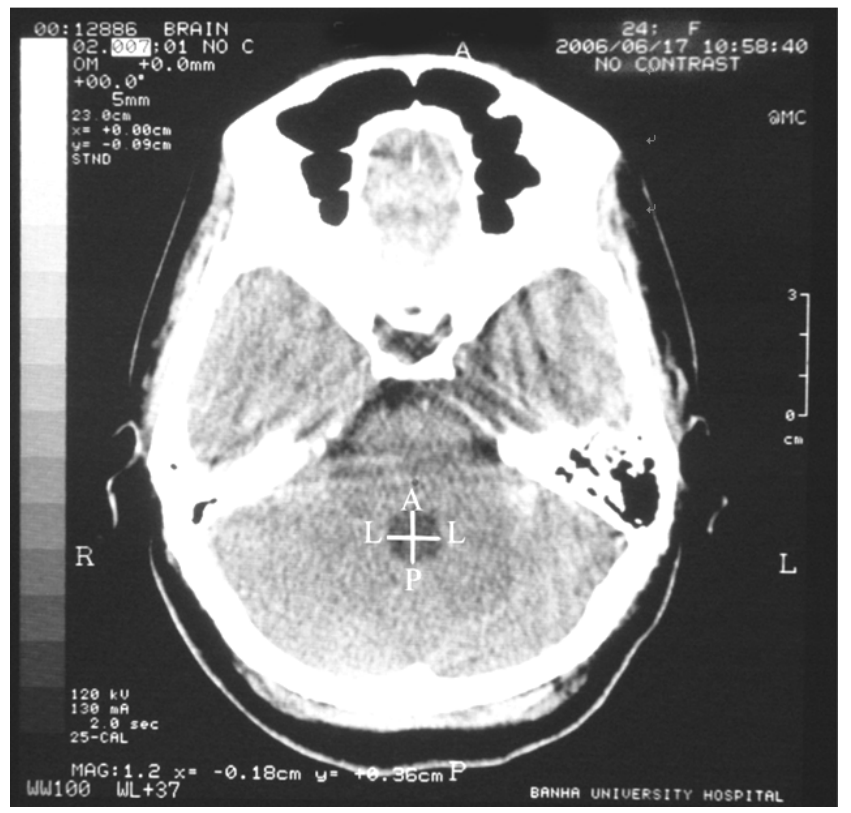

Figure (7). Axial CT image of fourth ventricular maximum width of a female aged 24 years old showing.

- The anteroposterior diameter of the fourth ventricle $(\mathrm{AP})=12.69 \mathrm{~mm}$.

- The laterolateral diameter of the fourth ventricle $(\mathrm{LL})=$ $12.69 \mathrm{~mm}$

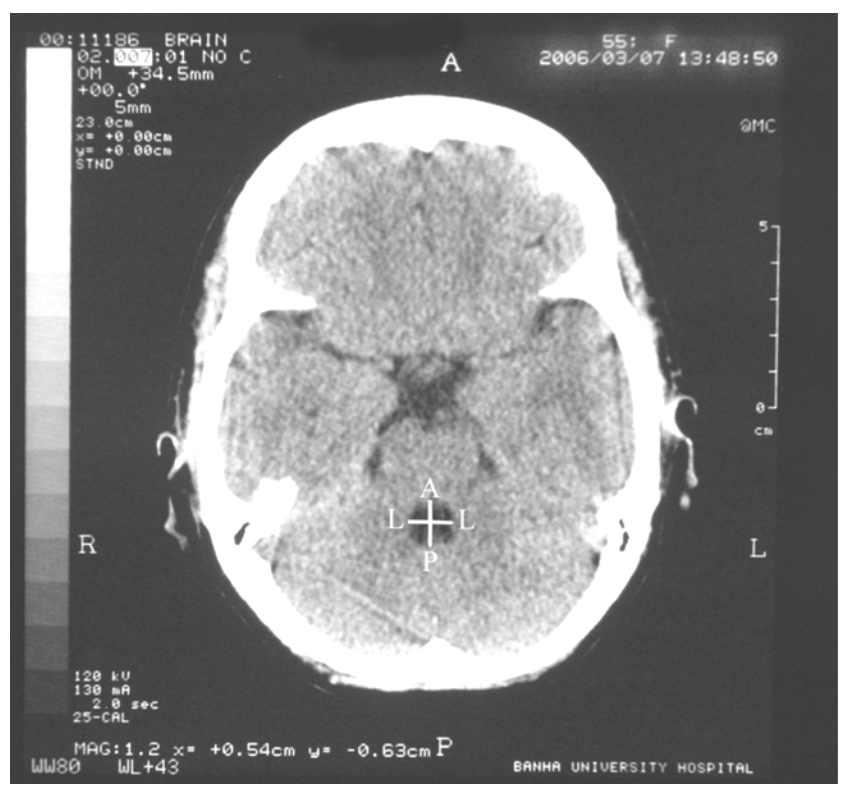

Figure (8). Axial CT image of fourth ventricular maximum width of a female aged 55 years old showing.

- The anteroposterior diameter of the fourth ventricle $(\mathrm{AP})=12.5 \mathrm{~mm}$.

- The laterolateral diameter of the fourth ventricle (LL) = $12.5 \mathrm{~mm}$. 


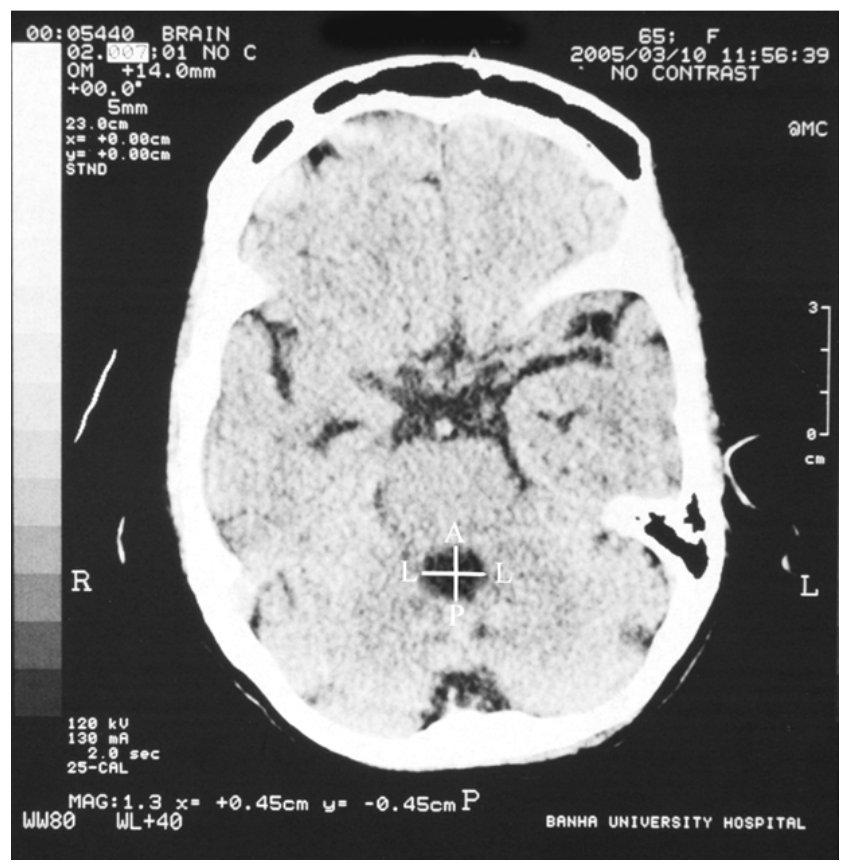

Figure (9). Axial CT image of fourth ventricular maximum width of a female aged 65 years old showing.

- The anteroposterior diameter of the fourth ventricle $(\mathrm{AP})=12.86 \mathrm{~mm}$.

- The laterolateral diameter of the fourth ventricle $(\mathrm{LL})=$ $12.86 \mathrm{~mm}$.

\subsection{Comparison Between Female and Male Parameters in the Four Tested Age Groups (Sex Difference)}

* The fourth ventricle:

\subsubsection{The Maximum Anteroposterior Diameter of the Fourth Ventricle (AP)}

In group one, two, three and four, the mean values of (AP) showed no statistical significant difference between males and females in the first and second groups, while in the third and fourth groups the mean values of males were significantly higher than those obtained from females (tables 6-9).

\subsubsection{The Laterolateral Diameter of the Fourth Ventricle (LL)}

In group one, two, three and four, the mean values of (LL) showed no significant difference between males and females in the first and second groups, while in the third and fourth groups the mean values of males were significantly higher than those obtained from females, (tables 6-9).

\subsubsection{The Maximum Intercaranial Diameter (CR)}

In group one, two, three and four, the mean values of (CR) were larger in males than in females, but this difference was insignificant in the first, second and fourth groups, while the third group only showed a significant difference between males and females (tables 6-9).

\subsubsection{Fourth Ventricular Indices $(A P / C R),(A P / L L)$ and (AP/ff)}

I- $(\mathrm{AP} / \mathrm{CR})$ : The mean values of this index was showed insignificant difference between males and females in the first three age groups and the fourth group only showed significant difference between males and females .

II- (AP/LL): The mean values of this index showed no statistical difference between males and females in the all tested age groups, so this ventricle is called sentinel fourth ventricular index as it is not changed by age or by sex.

III- (AP/ff): The mean values of this index showed insignificant difference between males and females in the first, second and fourth groups, while the third group only showed significant difference between males and females, (tables 6-9).

Table 6. Comparison between female and male parameters in the tested age groups (sex difference): fourth ventricle in females and males at the age of (0-19 years).

\begin{tabular}{llllll}
\hline & & FG1 & MG1 & t & p \\
\hline 4th & AP & $9.88 \pm 2.52$ & $9.24 \pm 3.08$ & 0.71 & $>0.05$ \\
ventricle & LL & $9.88 \pm 2.52$ & $9.24 \pm 3.08$ & 0.71 & $>0.05$ \\
& CR & $112 \pm 15.6$ & $118.4 \pm 6.34$ & 1.63 & $>0.05$ \\
& AP/CR & $0.09 \pm 0.02$ & $0.08 \pm 0.03$ & 1.24 & $>0.05$ \\
& AP/LL & $1 \pm 0$ & $1 \pm 0$ & - & - \\
& AP $\backslash f f$ & $0.35 \pm 0.1$ & $0.32 \pm 0.13$ & 0.81 & $>0.05$ \\
\hline
\end{tabular}

- $\mathrm{P}>0.05=$ Insignificant

- $\mathrm{P}<0.05=$ Significant.

- $\mathrm{P}<0.01=$ highly significant

Table (7). Comparison of the measured parameter of the brain fourth ventricle in females and males at the age of (20-39 years).

\begin{tabular}{llllll}
\hline & & FG2 & MG2 & t & P \\
\hline 4th & AP & $9.99 \pm 1.28$ & $10.3 \pm 2.73$ & 0.49 & $>0.05$ \\
ventr & LL & $9.99 \pm 1.28$ & $10.3 \pm 2.73$ & 0.49 & $>0.05$ \\
icle & CR & $119 \pm 4.29$ & $120 \pm 5.22$ & 0.72 & $>0.05$ \\
& AP/CR & $0.13 \pm 0.19$ & $0.09 \pm 0.02$ & 1.07 & $>0.05$ \\
& AP/LL & $1 \pm 0$ & $1 \pm 0$ & 1.27 & $>0.05$ \\
& AP $\backslash$ ff & $0.34 \pm 001$ & $0.33 \pm 0.1$ & 0.41 & $>0.05$ \\
\hline
\end{tabular}

- $\mathrm{P}>0.05=$ Insignificant.

- $\mathrm{P}<0.05=$ Significant.

- $\mathrm{P}<0.01=$ highly significant.

Table (8). Comparison of the measured parameters of the brain fourth ventricle in females and males at the age of (40-59) years.

\begin{tabular}{llllll}
\hline & & FG3 & MG3 & t & P \\
\hline 4th & AP & $12.1 \pm 0.92$ & $13.9 \pm 1.56$ & 3.84 & $<0.001$ \\
ventricle & LL & $12.1 \pm 0.92$ & $13.9 \pm 1.56$ & 3.84 & $<0.001$ \\
& CR & $116 \pm 4.93$ & $121 \pm 6.03$ & 3.02 & $<0.01$ \\
& AP/CR & $0.1 \pm 0.01$ & $0.7 \pm 2.4$ & 1.03 & $>0.05$ \\
& AP/LL & $1 \pm 0$ & $1 \pm 0$ & - & - \\
& AP $\backslash$ ff & $0.37 \pm 0.04$ & $0.41 \pm 0.06$ & 2.12 & $<0.05$ \\
\hline
\end{tabular}

- $\mathrm{P}>0.05=$ Insignificant

- $\mathrm{P}<0.05=$ Significant.

- $\mathrm{P}<0.01=$ highly significant. 
Table (9). Comparison of the measured parameters of the brain fourth ventricle in females and males at the age of ( $>60$ years).

\begin{tabular}{llllll}
\hline & & FG4 & MG4 & t & P \\
\hline 4th & AP & $14.2 \pm 1.32$ & $16.3 \pm 0.91$ & 4.14 & $<0.001$ \\
ventricle & LL & $14.2 \pm 1.32$ & $16.3 \pm 0.91$ & 4.14 & $<0.001$ \\
& CR & $116 \pm 2.57$ & $119 \pm 4.68$ & 1.78 & $>0.05$ \\
& AP/CR & $0.12 \pm 0.01$ & $0.14 \pm 0.01$ & 4.47 & $<0.001$ \\
& AP/LL & $1 \pm 0$ & $1 \pm 0$ & - & - \\
& AP $\backslash$ ff & $0.4 \pm 0.04$ & $0.41 \pm 0.03$ & 0.63 & $>0.05$ \\
\hline
\end{tabular}

- $\quad \mathrm{P}>0.05=$ Insignificant.

- $\mathrm{P}<0.05=$ Significant.

- $\mathrm{P}<0.01=$ highly significant.

\section{Discussion}

Cerebral atrophy has long been recognized by neuropathologists as a prominent feature of normal aging process. However, sever atrophy occurred only in demented elderly individuals and not in normal aged. Observations such as these have led to attempts to quantify cerebral atrophy antemortem, enhancing our understanding of pathophysiolog of normal brain aging (12).

In the midportion of twenteeth century cerebral atrophy could be detected invasively via pneumoencephalography. The earliest CT studies proved more than capable of demonstrating brain tissue loss in the elderly. Many investigators were able to document statistically significant correlations between age and both ventricular size and extent of cortical atrophy even with crude qualitative or semiquantiative estimates of CSF volumes (13).

The brain changes that occur as part of normal aging include ventricular and sulcal dilatation due to cerebral atrophy. On average, ventricular volume increases approximately two folds between young (ages 20 to 30) and elderly (ages 60 to 80 ) normal subjects. The ventricular volume remains relatively stable up to age 60 years, after which there is an accelerated increase in size (14).

The possibilities of differentiation between a "normal" and an "enlarged" ventricular system by means of computerized tomography are limited. The main problems are the definition of normal population and the fact that a certain methodical error in measurement is not to be avoided. On the other hand, that differentiation is essential for the diagnosis of ventricular enlargement and brain atrophy. The daily practice requires a method, which allows an accurate measurement as well as a quick and simple performance. The evaluation of the width of the ventricular system by CT linear measurement and ventricular indices is likely to meet all these requirements (15 \&16).

The present study confirms and augments past work of age and sex effect on brain aging and provides further evidence that brain structures in humans are differentially sensitive to the effects of both age and sex, and also in both sexes there were remarkable individual differences in brain atrophy. The results of this study are limited by a small group of cases and also limited by its cross-sectional design and need to be replicated with a larger group and with longitudinal data to truly demonstrate curves of brain atrophy and ventricular dilatation.

\subsection{Linear Measurements of the Fourth Ventricle}

In the present work, in both sexes the anteroposterior diameter (AP) and the laterolateral diameter (LL) of the fourth ventricles showed an insignificant increase between the first two groups $(\mathrm{P}>0.05)$. However there mean values showed a significant increase in the last three consecutive age groups (20-> 60) years. These data were consistent with Meese et al. (1980), (17) and Agapejev (2002), (10), who found that the fourth ventricle shows a continuous and progressive increase with advancing age. Koller et al. (1981),(18), found that the maximal anteroposterior (AP) and laterolateral (LL) width of the fourth ventricle, showed an insignificant increase with advance of age from 20 to 60 years at CT, but they found a significant increase in this parameter thereafter.

Due to the variability in the size of the films and in the head angularity of the accomplished exams impending the uniformity of direct measures for the study of the fourth ventricle, it was necessary to establish indices. In the present work $(\mathrm{AP} / \mathrm{CR})$ and $(\mathrm{AP} / \mathrm{ff})$ indices, showed no significant changes with sex and age, but these indices had some degree of changes during the human lifetime. On the other hand the only index that does not suffer influence of age and sex is the (AP/LL) index. Meese (1980), (17) and Agapejev (2002),(10), confirmed these present data and referred the stability of (AP/LL) index to the volumetric difference in the neuroaxis.

Accordingly there is a possibility to diagnose a lot of the brain insults by AP/LL index, which is in normal subjects the $\mathrm{AP} / \mathrm{LL}=1$. However, $\mathrm{AP} / \mathrm{LL}>1$ was found in all patients with clinical picture of benign intracranial hypertension and in psychiatric alterations as the first and most important manifestation. It also occurred in $86 \%$ of patients with cerebrovascular disturbances, in $74 \%$ with hydrocephalus, in $71 \%$ with epilepsy, in $64 \%$ with meningo-encephalitis, and in $50 \%$ with migraine like headache (Agapejev, 2002), (10).

\subsection{Regarding the Sex Difference in Ventricular Dilatation}

The mean values of AP, LL, CR, AP/CR, AP/ff of the fourth ventricle were higher in males than in females and showed significant differences in some of the mentioned parameters. However AP/LL was the only parameter which showed no difference between males and females as this index considered as sentinel index of the fourth ventricle which showed no changes with age and sex, (Agapejev, 2002),(10).

The present findings of the fourth ventricle were in agreement with Hatazawa et al. (1982), (19), who found a distinct difference observed between men and women in the process of brain atrophy with increasing age. Skullerud (1985),(20), found that women had smaller ventricles than men, but this difference was in proportion to the smaller size of their hemispheres. Also, Larkin (1998), (21), found that 
the shrinkage of brain was more rapid in men than in women.

The data of the present study were confirmed also by Lemaitre et al. (2005), (22), who found that men exhibiting larger grey matter and white matter and CSF comportment volumes than females regarding all the brain areas. Also, Carne et al. (2006), (23), cited that males have greater cerebral, cerebellar and cerebral cortical lobar volumes than females and the reduction of cerebral volumes with age is more marked in males than females. However, these results were corresponded closely to Raz et al. (1998), (24) and Walhovd et al. (2005), (25), who found significant age effects in both sexes for all brain parameters except for the fourth ventricle.

Also, regarding the sex difference the results of the present study were in disagreement with Xenose et al. (2002), (26) and Salat et al. (2004),(27), they all found that there is no sexual difference at all in the volumes of the brain and the level of brain atrophy in all brain areas (28\&29).

\section{Acknowledgment}

The authors wish to thank Dr. Ahmed Farid, Prof of Diagnostic Radiology and Dr. Khaled Salam, Prof of Neurology, Benha University Hospital, for their helpful assistance for this work to be conducted.

\section{References}

[1] Erten-Lyons D, Dodge HH, Woltjer R, Silbert LC, Howieson DB, Kramer P, Kaye JA: Neuropathologic basis of ageassociated brain atrophy. JAMA Neurol. 2013; 70(5):616-22.

[2] Fjell AM, Westlye LT, Grydeland H, Amlien I, Espeseth T, Reinvang I, Raz N, Holland D, Dale AM, Walhovd KB: Alzheimer Disease Neuroimaging Initiative: Critical ages in the life course of the adult brain: nonlinear subcortical aging. Neurobiol Aging. 2013; 34 (10): 2239-47.

[3] Marner L, Nyengaard JR, Tang Y, Pakkenberg B.: Marked loss of myelinated nerve fibers in the human brain with age. Journal of Comparative Neurology 2003; 462:144-52.

[4] Raz N, Lindenberger U, Rodrigue KM, Kennedy KM, Head D, Williamson A, et al.: Regional brain changes in aging healthy adults: General trends, individual differences and modifiers. Cerebral Cortex 2005; 15:1676-89.

[5] Ziegler G, Dahnke R, Jäncke L, Yotter RA, May A, Gaser C: Brain structural trajectories over the adult lifespan. Hum Brain Mapp. 2012; 33(10): 2377-89.

[6] Taki Y, Thyreau B, Kinomura S, Sato K, Goto R, Wu K, and Kawashima R, Fukuda H: A longitudinal study of age- and gender-related annual rate of volume changes in regional gray matter in healthy adults. Hum Brain Mapp. 2013; 34(9):2292301.

[7] Purves D, Augustine GJ, Fitzpatrick D, et al., editors. Neuroscience. 2nd edition. Sunderland (MA): Sinauer Associates; 2001
[8] Zaharia B, Pleşea IE, Georgescu CC, Cameniță A, Georgescu $\mathrm{CV}$, Enache SD, Tnovici M: Morphoclinical study of intracerebral hemorrhage with intraventricular extension. Rom J Morphol Embryol. 2005; 46 (3):199-206.

[9] Dănăilă L: Primary tumors of the lateral ventricles of the brain. Chirurgia (Bucur). 2013; 108(5):616-30.

[10] Agapejev S: Fourth ventricle computed tomography: standardization and characteristics, Arq. Neuro. Psiquiatr, 2002; 60: 211-218.

[11] Hagga JR, Lanzieri CF, Gilkenson RC: "CT and MRI imaging of the whole Body" fourth edition, volume 1, chapter 4, Mosby, Inc. Philadelphia, USA, 2003; P. 88-123 and 351.

[12] Durazzo, T.C.; Cardenas, V.A.; Studholme, C.; Weiner, M.W. and Meyerhoff, D.J. (2007): Non-treatment- seeking heavy drinkers: Effects of chronic cigarette smoking on brain structure, Drug Alcohol Depend.; 87 (1): 76-82.

[13] Mortamet, B.; Zeng, D.; Gering, G.; Prastawa, M. and Bullitt, E. (2005): Effects of healthy aging measured by intracranial compartment volumes using a designed MR brain database, Int. Conf. Med. Image Comput. Assist. Interv; 8 (pt 1): 383391.

[14] Hagga, J.R.; Lanzieri, C.F. and Gilkenson, R. C. (2003): "CT and MRI imaging of the whole Body" fourth edition, volume 1, chapter 4, Mosby, Inc. Philadelphia, USA, P. 88-123 and 351 .

[15] Wanifuchi, H.; Shimizu, T. and Maruyama, T. (2002): Agerelated changes in the proportion of intracranial cerebrospinal fluid space measured using volumetric computerized tomography scanning, J. Neurosurg.; 97 (3): 607-610.

[16] Gur, R.C.; Gunning, D.F.; Turetsky, B.I.; Bilker, W.B. and Gur, R. E. (2002): Brain region and sex differences in age association with brain volume, Am. J. Geriatr. Psychiatry; 10 (1): $72-80$.

[17] Meese, W.; Kluge, W.; Grumme, T. and Hopfenmuller, W. (1980): CT evaluation of the CSF spaces of healthy persons. Neuroradiology; 19: 131-136.

[18] Koller, W.C.; Glatt, S.L.; Perlik, S.; Huckman, M.S. and Fox, J.H. (1981): Cerebellar atrophy demonstrated by computed tomography. Neurology ; 31: 405-412.

[19] Hatazawa, J.; Ito, M.; Yamaura, H. and Matsuzawa, T. (1982): Sex difference in brain atrophy during aging, a quantitative study with computed tomography, J. Am, Geriatr. Soc.; 30 (4): 235-239.

[20] Skullerud, K. (1985): Variations in the size of the human brain Influence of age, sex, body length body mass index, alcoholism, Alzheimer changes and cerebral atherosclerosis, Acta neurol. Scand. Suppl.; 102: 91-94.

[21] Larkin, M. (1998): Brain shrinkage more rapid in men than in women, lancet; 351 (9102): 575-576.

[22] Lemaitre, H.; Crivello, F.; Grassiot, B.; Alperovitch, A.; Tzourio, C. and Mazoyer, B. (2005): Age and sex- related effects on the neuroanatomy of healthy elderly, Neuroimage.; 26 (3) 900-911.

[23] Carne, R.P.; Vogrin S.; Litewka, L. and Cook, M.J. (2006): Cerebral cortex: on MRI- based study of volkume and variance with age and sex, J. Clin. Neuro Sci.; 13 (1) 60-72. 
[24] Raz, N.; Dupuis, J. H.; Briggs, S.D.; Mc Gavran, C. and Acker, J.D. (1998): Differential effects of age and sex on the cerebellar hemispheres and the vermis: A prospective MR study, Am. J. Neuroadiol.; 19: 65-71.

[25] Walhovd, K.B.; Fjell, A.M.; Reinvang, I.; Lundervold, A. and Dale, A.M. (2005): Effects of age on volumes of cortex, white matter and subcortical structures, Neurobiol Aging; 26 (9): 1261- 1270 .

[26] Xenose, C.; Sgouros, S. and Natarjan, K. (2002): Ventricular volume change in childhood, J. Neurosurg.; 97 (3): 584-590.

[27] Salat, D.H.; Buckner, R.L.; Synder, A.Z.; Grere, D.N. and
Fischl, B. (2004): Thinning of the cerebral cortex in aging, Cereb. Cortex; 14 (7): 721-730.

[28] J.D. Usman, G.H. Yunusa, S.A. Saidu, A.D. Zagga, A. Bello, A. Abdulhameed, S.S. Bello, A.A. Tadros and S.M. Bello: Cephalometric Assessment of the Fourth Ventricles Using Computerized Tomography: A Five Year Study in Usmanu Danfodiyo University Teaching Hospital (UDUTH), Sokoto. Nigerian Journal of Basic and Applied Science (September, 2012), 20(3): 208-212.

[29] Rabindra N. Padhy: Age-related Changes in Ventricular System of Brain in Normal Individuals Assessed by Computed Tomography Scans. vol 66, No. 6, November-December 2014. 